\title{
Interfacial Control of the Synthesis of Cellulose Nanocrystal Gold Nanoshells
}

\author{
Rasool Nasseri, $\ddagger^{\mathrm{a}, \mathrm{b}}$ Yebin Lee, $\ddagger^{\mathrm{a}, \mathrm{b}}$ and Kam C. Tam ${ }^{* a, b}$
}

${ }^{a}$ Department of Chemical Engineering, University of Waterloo, 200 University Avenue West, Waterloo, Ontario, Canada N2L 3G1

${ }^{b}$ Waterloo Institute for Nanotechnology, University of Waterloo, 200 University Avenue West, Waterloo, Ontario, Canada N2L 3G1 
Supporting Information:

Table S1. Zeta potential of CNC-PDADMAC-Aushells prepared by the ex-situ method

\begin{tabular}{ccccccc}
\hline \multirow{2}{*}{ Capping Agent } & Round of Shell & \multicolumn{5}{c}{ Amount of gold plating Solution } \\
\cline { 3 - 7 } & $\begin{array}{c}\text { Growth } \\
\text { TSC }\end{array}$ & $0.5 \mathrm{~mL}$ & $1.0 \mathrm{~mL}$ & $1.5 \mathrm{~mL}$ & $2.0 \mathrm{~mL}$ & $2.5 \mathrm{~mL}$ \\
& $1^{\text {st }}$ & $22.3 \pm 0.5$ & $25.9 \pm 0.4$ & $7.9 \pm 0.3$ & $\mathbf{- 1 8 . 1} \pm \mathbf{0 . 1}$ & $-0.8 \pm 0.2$ \\
\multirow{2}{*}{ THPC } & $2^{\text {nd }}$ & $19.2 \pm 0.2$ & $4.6 \pm 0.3$ & $-11.8 \pm 1.1$ & $\mathbf{- 9 . 5} \pm \mathbf{0 . 2}$ & $-7.7 \pm 0.2$ \\
& $1^{\text {st }}$ & $2.0 \pm 0.9$ & $15.5 \pm 0.3$ & $\mathbf{2 . 4} \pm \mathbf{0 . 2}$ & $0.0 \pm 0.2$ & $24.9 \pm 1.6$ \\
& $2^{\text {nd }}$ & $7.6 \pm 0.5$ & $-12.6 \pm 0.5$ & $\mathbf{- 1 8 . 5} \pm \mathbf{0 . 2}$ & $-1.7 \pm 0.2$ & $-12.3 \pm 0.5$ \\
\hline
\end{tabular}

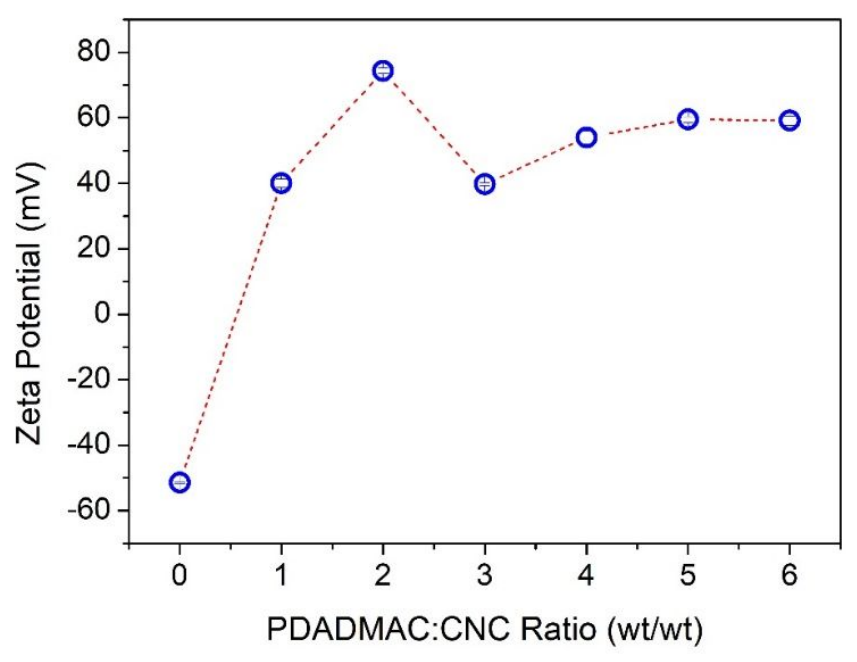

Figure S1. Zeta potential of CNC-PDADMAC suspensions comprising different ratios of PDADMAC:CNC after three times of ultrafiltration.

\section{FTIR analysis of freeze-dried CNC-PDADMAC}

FTIR analysis of freeze-dried CNC-PDADMAC suspension after three ultrafiltration cycles also confirmed the successful wrapping of CNC by PDADMAC. The peaks at $2865 \mathrm{~cm}^{-1}$ and $1475 \mathrm{~cm}^{-1}$ in CNC-PDADMAC FTIR spectra (these peaks are not observed for pristine CNC spectra) could be assigned to the methyl $\left(-\mathrm{CH}_{3}\right)$ stretching and quaternary ammonium group $\left(-\mathrm{N}^{+}\left(\mathrm{CH}_{3}\right)_{2}\left(\mathrm{CH}_{2}\right)_{2}\right)$ bending vibration of pyrrolidinium rings of PDADMAC, respectively ${ }^{35}$ (Figure S2). 


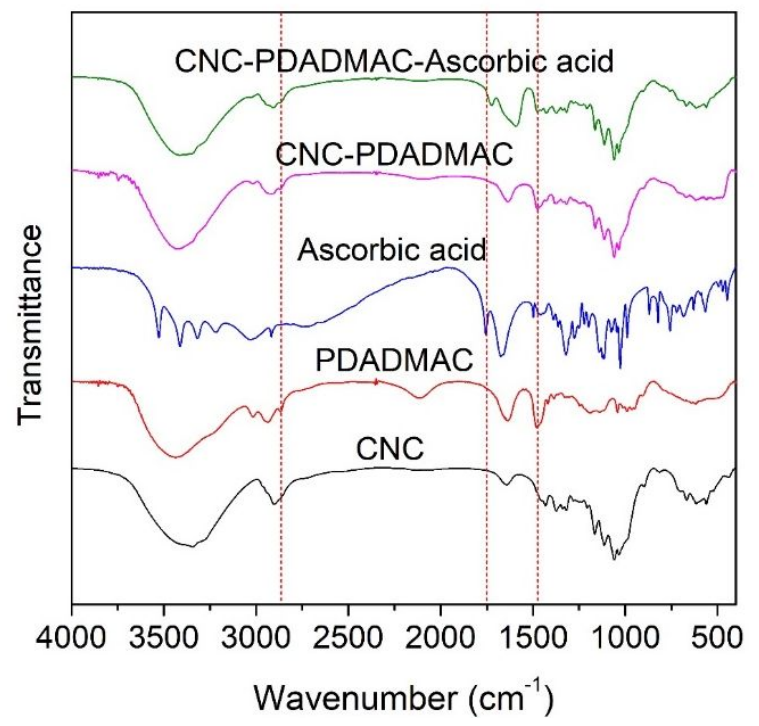

Figure S2. FTIR spectrums of pure CNC, PDADMAC, ascorbic acid, CNC-PDADMAC, and CNC-PDADMACAscorbic acid.
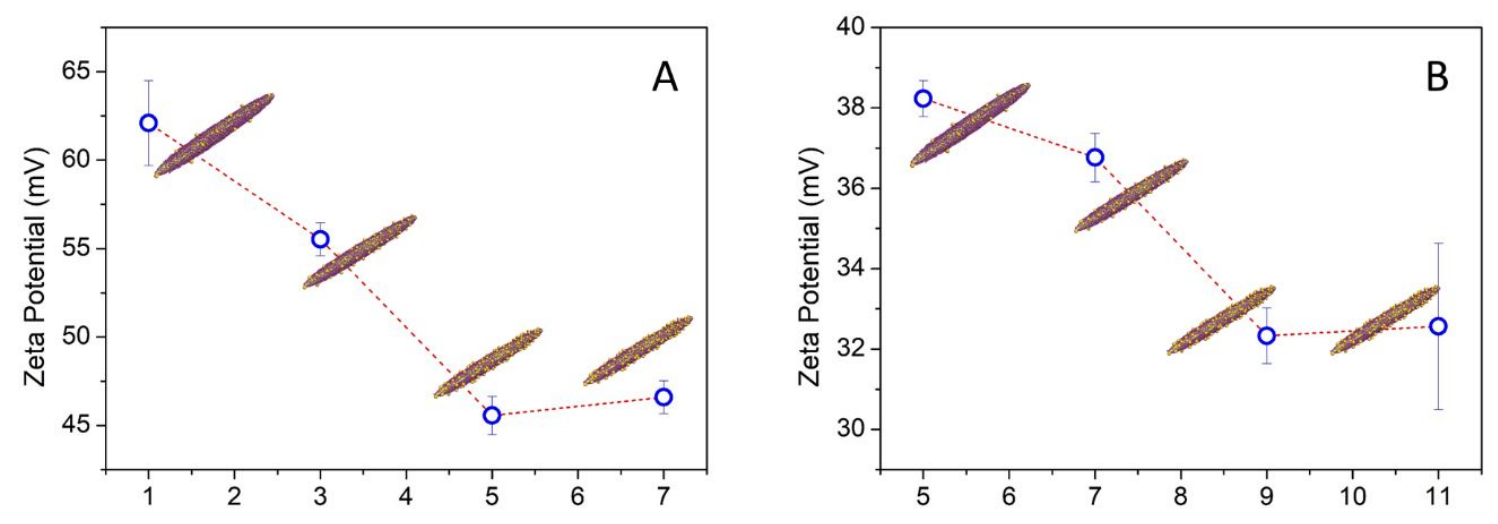

Au Seeds Solution : CNC-PDADMAC Volume Ratio $(\mathrm{mL} / \mathrm{mL})$ Au Seeds Solution : CNC-PDADMAC Volume Ratio $(\mathrm{mL} / \mathrm{mL})$

Figure S3. Zeta potential of CNC-PDADMAC-AuNPs prepared by adding different volumes of gold seed solution capped by (A) TSC and (B) THPC. 

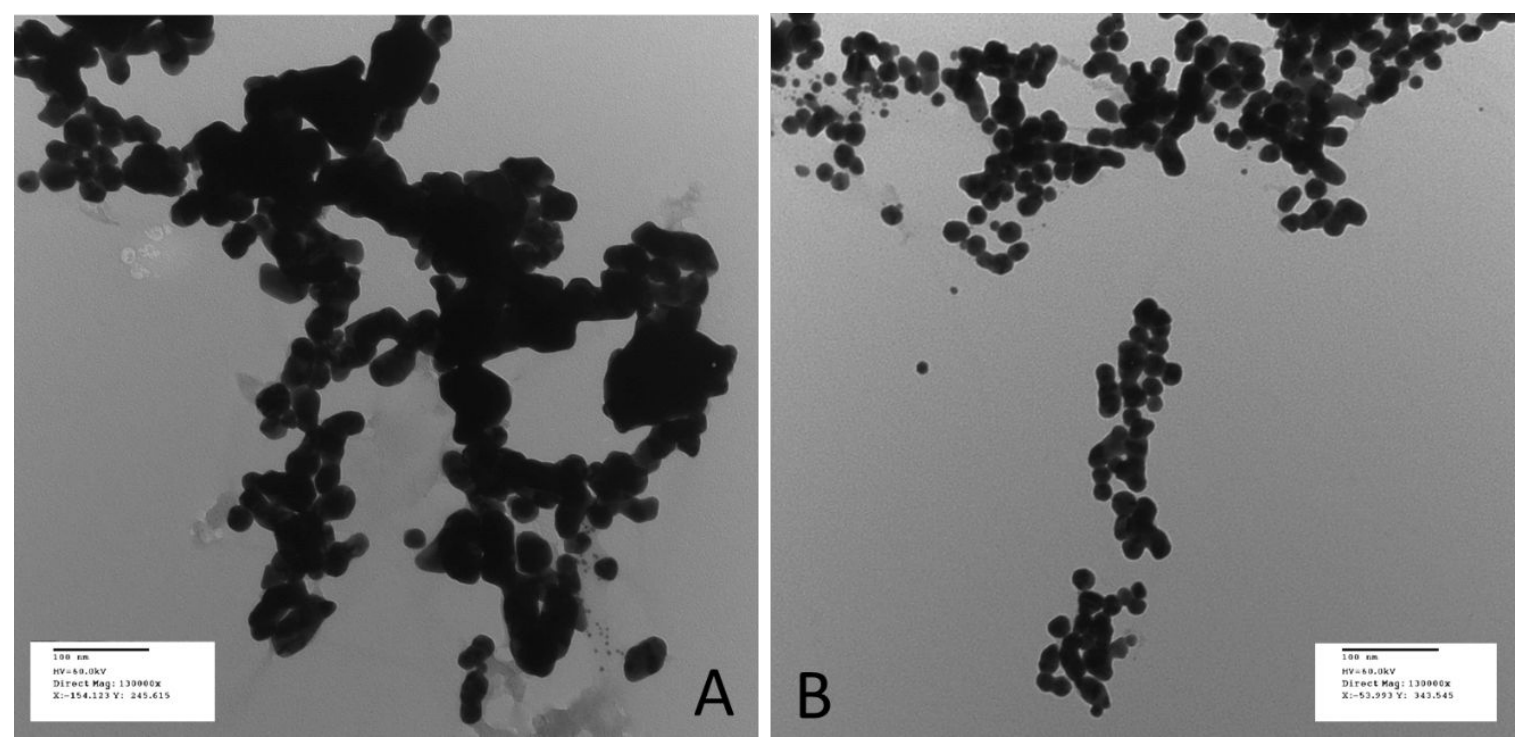

Figure S4. TEM images of aggregates of CNC-gold nanoshells prepared from CNC-PDADMAC-AuNPs. (A) TSC capped AuNPs and (B) THPC capped AuNPs.
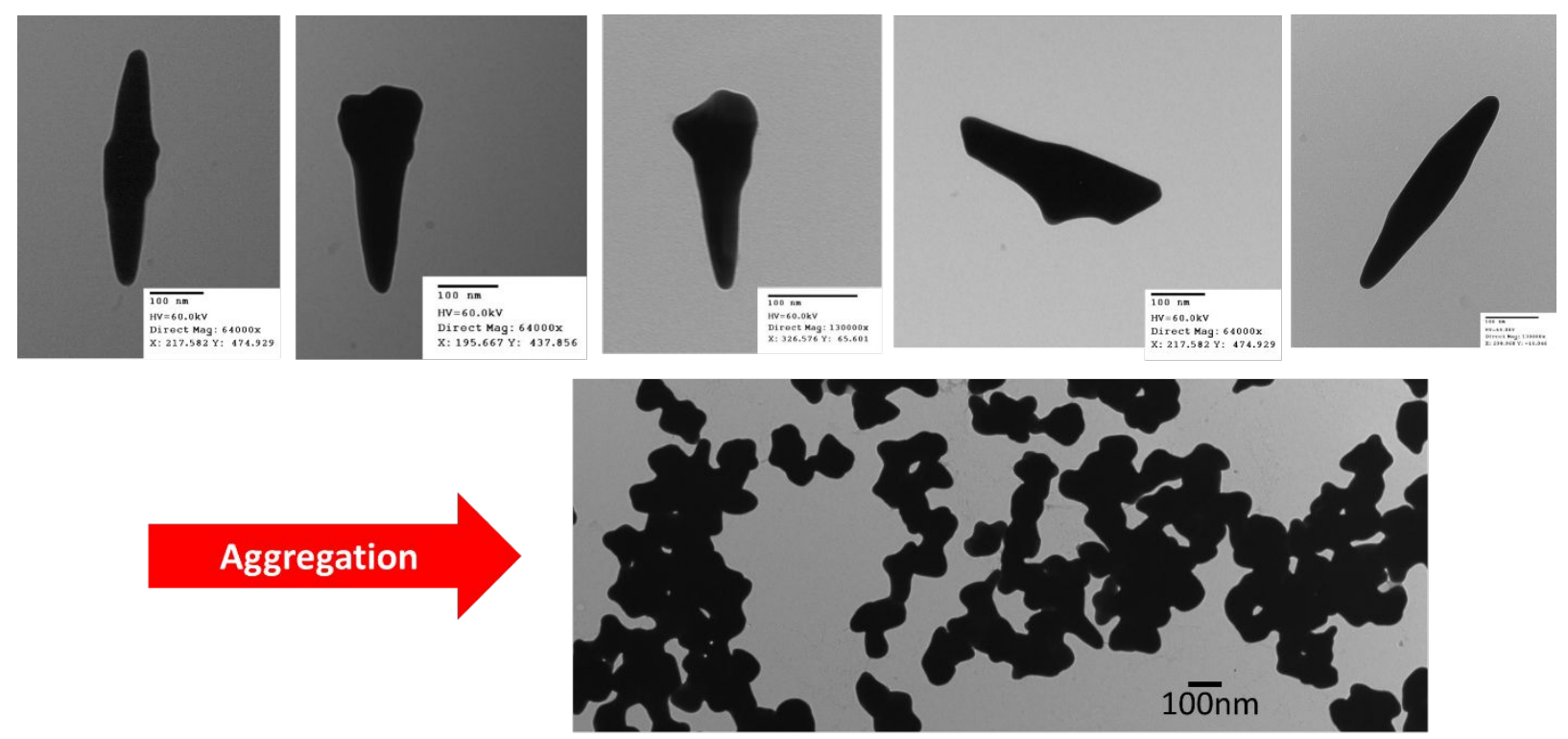

Figure S5. TEM images of a few individual CNC-Aushells along with an aggregate of several CNC-Aushells. Scalebars are $100 \mathrm{~nm}$.

\section{Optimization of the in-situ method}

First, decorated CNC (CNC-PDADMAC-AuNPs) prepared by TSC capped AuNPs (50 mL, 0.04 wt\%) was mixed with ascorbic acid (5 mL, $0.05 \mathrm{M})$. The $\mathrm{pH}$ was not adjusted and was around 2. 
Then, CTAB gold plating solution $(100 \mathrm{~mL})$ was added dropwise $\left(40 \mathrm{~mL} \mathrm{~h}^{-1}\right)$. Figure $\mathrm{S} 6$ shows the TEM image of the resulting CNC gold-nanostructures. Some bare CNC-PDADMAC nanoparticles were observed along with some free gold nanoparticles. The detachment of AuNPs from the CNC-PDADMAC surfaces led to the formation of free gold nanoparticles. The growth of these free gold nanoparticles consumed the available gold ions in the solution resulting in some bare CNC-PDADMAC nanoparticles. Cross-linking between some CNC Aushells also was observed in this sample.
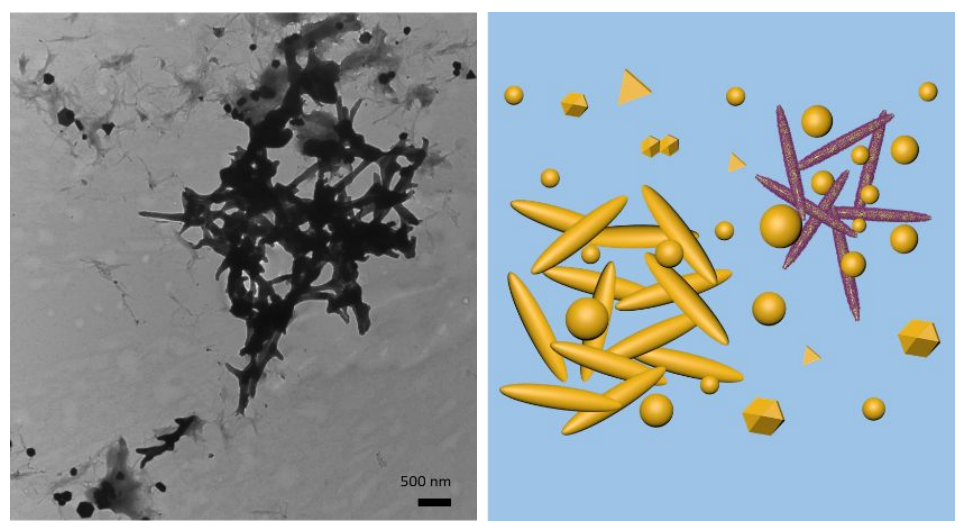

Figure S6. TEM image of CNC gold-nanostructures prepared by CNC-PDADMAC-AuNPs in the in-situ method.

The effect of $\mathrm{pH}$ and temperature on the morphology of Aushells were also investigated. In one experiment CNC-PDADMAC suspension (50 mL, $0.04 \mathrm{wt} \%)$ was mixed with an ascorbic acid solution ( $5 \mathrm{~mL}, 0.05 \mathrm{M})$ without adjusting the $\mathrm{pH}(\mathrm{pH}$ was around 2). The mixture was stirred for $1 \mathrm{~h}$ at $30^{\circ} \mathrm{C}$ and then $\mathrm{CTAB}$ gold plating solution $(100 \mathrm{~mL})$ was added to the mixture by a syringe pump $\left(40 \mathrm{~mL} \mathrm{~h}^{-1}\right)$ under mild stirring at $30^{\circ} \mathrm{C}$. In the other experiment, after mixing $\mathrm{CNC}-$ PDADMAC suspension $(50 \mathrm{~mL}, 0.04 \mathrm{wt} \%)$ and ascorbic acid solution $(5 \mathrm{~mL}, 0.05 \mathrm{M}), \mathrm{pH}$ was adjusted to around 5 and then $\mathrm{CTAB}$ gold plating solution $(100 \mathrm{~mL})$ was added to the mixture by 
a syringe pump $\left(40 \mathrm{~mL} \mathrm{~h}^{-1}\right)$ under mild stirring at $80^{\circ} \mathrm{C}$. TEM images of resulting $\mathrm{CNC}$-gold nanostructures are shown in Figure S6. Rough, incomplete, and discontinuous surface morphology was observed in the TEM images of the Aushells prepared without adjusting the pH, Figure S7A. TEM image of the Aushells prepared at $80^{\circ} \mathrm{C}$ showed a complete but very rough and uneven surface morphology, Figure S7B. Morphology of the Aushell prepared by adjusting the pH to 5 and at $30^{\circ} \mathrm{C}$ was presented in Figure $\mathrm{S} 7 \mathrm{C}$ for comparison.
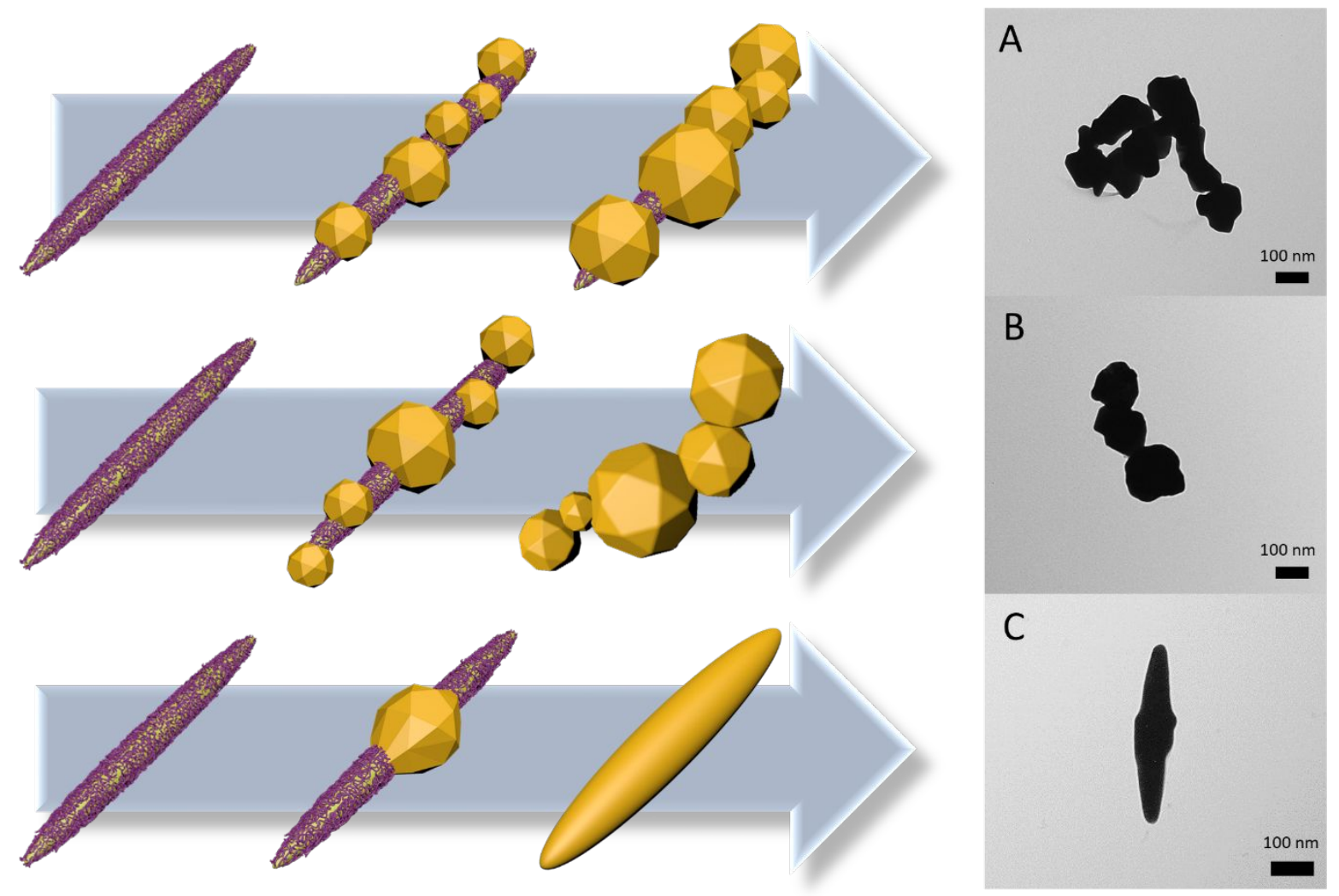

Figure S7. TEM images of CNC-gold nanostructures prepared by different reaction conditions: (A) $\mathrm{pH} \sim 2$ at $30^{\circ} \mathrm{C}$, (B) $\mathrm{pH} \sim 5$ at $80{ }^{\circ} \mathrm{C}$ and, (C) $\mathrm{pH} \sim 5$ at $30^{\circ} \mathrm{C}$. 